\title{
Study of nuclear sizes in the centres of malignant and benign lymphoid follicles
}

\author{
J CROCKER, EL JONES, RC CURRAN
}

From the Department of Pathology, The Medical School, University of Birmingham, Birmingham, B15 2TJ

SUMMARY The sizes of follicle centre cells in 15 specimens of follicular (centroblastic-centrocytic) non-Hodgkin's lymphoma and 15 specimens of reactive follicular hyperplasia have been measured. The findings differ from previous studies, where nuclei of cells from follicle centres and interfollicular areas were measured and revealed no significant difference between follicular lymphoma and reactive follicular hyperplasia. In the current study, by measuring only follicle centre cell nuclei, it has been found that, in reactive follicular hyperplasia, the mean nuclear maximum diameter $\left(D_{\max }\right)$ and area are significantly greater than in centroblastic-centrocytic follicular lymphoma. In addition, the standard deviation of these data is greater for reactive follicular hyperplasia than follicular lymphoma, implying greater "scatter" or heterogeneity of the nuclear sizes in the follicle centre cells of the former than the latter. Thus, the size of these cells appears to be of value as an histological discriminator between these benign and malignant conditions.

Various criteria have been suggested in the past as aids to the histological distinction between follicular non-Hodgkin lymphomas and reactive follicular hyperplasia. ${ }^{1-4}$ Quantitative studies, such as enumeration of the macrophage content of follicular lymphoma and reactive follicular hyperplasia specimens $^{5}$ and the measurement of mean nuclear maximum diameter $\left(D_{\max }\right)$, area and form factor ${ }^{67}$ have not proved useful in distinguishing between these two types of specimen. In these latter studies, however, nuclei of cells within the follicle centres, marginal zones and in areas between the follicles were measured which may have led to falsely-low data with respect to reactive follicular hyperplasia. In addition in follicular lymphoma, the interfollicular cells may or may not be malignant. To investigate the possibility of differentiating follicular lymphoma from reactive follicular hyperplasia by virtue of nuclear size, the mean nuclear $D_{\max }$ and area have been measured in a series of such specimens. However, in an attempt to measure only (or principally) malignant cells in follicular lymphoma, nuclei in the follicle centres have been specifically selected. Similarly, only nuclei in the centres of follicles in reactive follicular hyperplasia have been measured.

\section{Material and methods}

LYMPH NODES

Thirty lymph nodes were examined, from the same

Accepted for publication 27 July 1983 number of patients. The 15 specimens of follicular lymphoma were morphologically all of the follicula centroblastic-centrocytic type and the other 1 is specimens were cases of reactive follicular hyperpolasia. To ensure that the pathological nature of the specimens of follicular lymphoma was truly malignant, specimens which had relentlessly disseminated, caused death of the patient or occurred in extranodal sites were chosen. Similarly, reactive nodes were selected whose aetiology was serologically or otherwise established (Tables 1 and 2).

\section{FIXATION AND STAINING}

The nodes were processed as described before. ${ }^{6-8}$ They were cut into $2 \mathrm{~mm}$ thick slices after surgical 욱 excision, and the slices fixed for $24 \mathrm{~h}$ in $10 \%$ formol-saline, processed to paraffin wax, sectioned at $4 \mu \mathrm{m}$ and stained by Harris's haematoxylin and eosin. The sections were dehydrated, cleared and mounted in balsam prior to the measurement procedure.

\section{MEASUREMENT OF NUCLEI}

The use of the MOP-AMO $\mathrm{Mas}_{3}$ heen described in detail previously..$^{5-8}$ As before, the machine was $\omega$ used in conjunction with a light microscope with a camera lucida drawing tube. The images of $500 \stackrel{0}{\circ}$ nuclei were outlined and for each specimen the his- $\mathbb{D}$ togram and mean values for $D_{\max }$ and area were given by the microprocessor. Sections were viewed under a $\times 100$ oil-immersion lens. Unlike previous 
Table 1 Mean nuclear dimensions in specimens of reactive follicular hyperplasia (follicle centres)

\begin{tabular}{|c|c|c|}
\hline $\begin{array}{l}\text { Diagnosis or serologically/ } \\
\text { clinically demonstrable } \\
\text { infective agent }\end{array}$ & $\begin{array}{l}\text { Mean nuclear } \\
D_{\max }(\mu m)\end{array}$ & $\begin{array}{l}\text { Mean nuclear } \\
\text { area }\left(\mu^{2}\right)\end{array}$ \\
\hline $\begin{array}{l}\text { Rheumatoid arthritis } \\
\text { Infectious mononucleosis } \\
\text { Toxoplasmosis } \\
\text { Draining carcinoma of colon } \\
\text { Draining carcinoma of colon } \\
\text { Yersinia pseudotuberculosis } \\
\text { Draining carcinoma of breast } \\
\text { Draining carcinoma of larynx } \\
\text { Rheumatoid arthritis } \\
\text { Draining carcinoma of breast } \\
\text { Draining carcinoma of colon } \\
\text { Toxoplasmosis } \\
\text { Toxoplasmosis } \\
\text { Cat-scratch disease } \\
\text { Draining carcinoma of breast }\end{array}$ & $\begin{array}{l}11.8(5.4) \\
11.9(5.2) \\
12.4(5.6) \\
12.5(5.4) \\
12.7(4.9) \\
12.9(5.2) \\
13.1(4.9) \\
13.4(5.6) \\
13.6(6.3) \\
13.6(4.8) \\
13.8(5.9) \\
13.9(5.8) \\
14.0(4.9) \\
14.1(5.6) \\
14.2(6.1)\end{array}$ & $\begin{array}{l}110(26) \\
104(24) \\
104(26) \\
102(28) \\
103(31) \\
110(27) \\
111(28) \\
107(34) \\
122(36) \\
117(28) \\
119(22) \\
109(37) \\
126(38) \\
139(39) \\
127(34)\end{array}$ \\
\hline
\end{tabular}

Standard deviations for each mean measurement are given in parentheses.

studies, ${ }^{67}$ where nuclei of cells in both the follicles and interfollicular areas were measured, only those in the follicle centres were outlined. This was facilitated by initial examination of lower-power $(\times 10)$ fields and the interposition of a simple eyepiece grid in the follicle centre areas, excluding the small lymphocyte "mantle zone" or interfollicular regions. Follicles were selected at random. ${ }^{8}$

As before ${ }^{6}$, the MOP-AMO ${ }_{3}$ was programmed to exclude nuclei with a $D_{\max }$ of $<5 \mu \mathrm{m}$ or area of $<50 \mu \mathrm{m}^{2}$. Section thickness corrections were applied using the method of Weibel.9

Statistical differences between pooled groups of data were determined by means of the Student's paired $t$ test.

\section{Results}

Tables 1 and 2 show the mean nuclear $D_{\max }$ and area for follicle centre cells in reactive and malignant fol-

Table 2 Mean nuclear dimensions in specimens of follicular centroblastic-centrocytic lymphoma (follicle centres)

\begin{tabular}{|c|c|}
\hline Mean nuclear $D_{\max }(\mu m)$ & Mean nuclear area $\left(\mu^{2}\right)$ \\
\hline 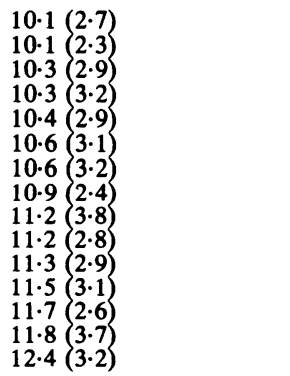 & $\begin{array}{r}77(14) \\
77(17) \\
75(13) \\
76(14) \\
81(17) \\
78(20) \\
79(13) \\
84(14) \\
82(15) \\
85(18) \\
86(18) \\
89(15) \\
94(16) \\
91(17) \\
101(23)\end{array}$ \\
\hline
\end{tabular}

Standard deviations for each mean measurement are given in parentheses. licles, respectively. The mean nuclear $D_{\max }$ for cells in reactive follicles ranges from $11.8-14.2 \mu \mathrm{m}$ whereas the mean nuclear $D_{\max }$ has values of $10 \cdot 1-$ $12.4 \mu \mathrm{m}$ in the case of malignant follicles. The corresponding standard deviations for reactive follicles are $4 \cdot 8-6 \cdot 3 \mu \mathrm{m}$ and $2 \cdot 3-3 \cdot 8 \mu \mathrm{m}$ for their malignant counterparts.

The mean nuclear area of follicle centre cells in reactive lymphoid follicles ranges from 102$139 \mu \mathrm{m}^{2}$; in malignant follicles the values extend from 75-101 $\mu \mathrm{m}^{2}$. The SDs for reactive follicle centre cells are from $22-39 \mu \mathrm{m}^{2}$ and for malignant follicle centre cells range from 13-23 $\mu \mathrm{m}^{2}$.

The range of values for mean $D_{\max }$ for follicle centre cells in reactive nodes is significantly greater than those in malignant follicles $(p<0.001)$. The same is true for the SD of $D_{\max }(p<0.001)$. Similarly, the mean nuclear area of follicle centre cells in reactive nodes is significantly $(p<0.001)$ greater than that of follicle centre cells in centroblasticcentrocytic lymphoma, as is the SD of nuclear area $(\mathrm{p}<0.001)$.

\section{Discussion}

The histological distinction between florid "reactive" follicular hyperplasia and follicular lymphoma often presents diagnostic problems. Accordingly, several authors have proposed criteria to aid in this problem $;{ }^{1-4}$ features such as nuclear pleomorphism, mitotic frequency, the presence of a marginal "mantle zone" or of tingible body macrophages have been proposed. However, these features are all based on subjective assessment.

Previously, we have investigated the usefulness of an objective approach based on quantitative measurements as means of differentiating between reactive follicular hyperplasia and follicular lymphoma. Mean nuclear $\mathrm{D}_{\max }$ and area measurements were not helpful, 7 reactive follicular hyperplasia and follicular lymphoma having similar ranges. However, in this study, the nuclei of both follicle centre, "mantle zone" and interfollicular cells were measured. Thus in follicular lymphoma both malignant (follicular) and reactive (interfollicular) cells were included. In an attempt to arrive at a better, measurable comparative cell population, it was later felt that follicle centre cells alone should be measured. This technique should give a direct comparison between malignant (follicular lymphoma) and reactive, benign (reactive follicular hyperplasia) cells.

In this study, as before, ${ }^{8}$ specimens were selected which were, in the case of reactive follicular hyperplasia, of known aetiology or in the case of follicular lymphoma had a relentless disseminating course or were tumours in extranodal sites. Thus tautological comparisons have been avoided, the natural history 
of both groups being confirmed.

The use of a simple squared eyepiece graticule readily enables the selection of follicle centre area and the results show that the mean nuclear $D_{\max }$ and $S D$ of mean $D_{\max }$ for cells here are greater in reactive follicular hyperplasia than in (centroblasticcentrocytic) follicular lymphoma. The same is true for mean nuclear area and SD of nuclear area. Thus not only is the mean nuclear size greater in reactive follicular hyperplasia than follicular lymphoma but so also is the SD of the measured values, implying a wider scatter and heterogeneity of nuclear dimensions in the former. This concurs with subjective impressions. Indeed, the reactive follicle centre includes centrocytes, centroblasts, macrophages (and related cells) whereas centrocytes greatly predominate over centroblasts in centroblasticcentrocytic lymphoma. ${ }^{10}$ The latter feature no doubt also accounts for the lower mean nuclear size in centroblastic-centrocytic follicular lymphoma than in reactive follicular hyperplasia.

Other quantitative techniques which we have applied to lymphoid tissue, partly in an attempt to distinguish between reactive follicular hyperplasia and follicular lymphoma, have included the enumeration of macrophages (by virtue of their content of alpha-naphthyl acetate esterase) ${ }^{5}$ and the measurement of shape (form factor) of these same cells. "It was shown that both low-grade non-Hodgkin's lymphoma and specimens of reactive follicular hyperplasia contained up to $4 \cdot 1$ and $3.2 \%$ of esterasepositive cells respectively (other than $\mathrm{T} \mu$ lymphocytes); thus the contribution of these cells, in haematoxylin-eosin preparations, should make little significant difference to the values for nuclear $D_{\max }$ and area of follicle centre cells in the current study. The mean form factor of the esterase-positive cells in both low-grade non Hodgkin's lymphoma and in reactive follicular hyperplasia was similarly low (in contrast to high-grade non Hodgkin's lymphoma), implying that irregular or branching forms predominate. ${ }^{11}$ A study of macrophage numbers, by virtue of their content of $\alpha$-naphthyl acetate or acid phosphatase content, in follicle centres in reactive follicular hyperplasia and follicular lymphoma, also showed no difference between these two conditions. ${ }^{12}$

Follicle size and the contribution of the "mantle zone" have also recently been measured, using the MOP- $\mathrm{AMO}_{3} .{ }^{8}$ It was found that mean follicle area was greater in reactive follicular hyperplasia than in centroblastic-centrocytic follicular lymphoma; the standard error of mean of the values was also greater in reactive follicular hyperplasia implying a greater heterogeneity of follicle sizes than in follicular lymphoma. Although the mean form factor was the same in reactive follicular hyperplasia and follicular lymphoma, the standard error of mean was greater $\overrightarrow{\vec{F}}$ in reactive follicular hyperplasia than follicular lym- 을 phoma, again suggesting greater heterogeneity of follicle shape in the former than in the latter. A "mantle zone" was present in all of the reactive follicles measured but only rarely observed in the specimens of follicular lymphoma.

It appears, therefore, that morphometric techni- $\triangle$ ques help the pathologist to distinguish between $\%$ reactive follicular hyperplasia and follicular lym- $\overrightarrow{0}$ phoma. The most useful measurements are those of follicle size ${ }^{8}$ and of mean nuclear $D_{\max }$ and area of $\vec{\omega}$ follicle centre cells. The presence of a "mantle zone" of small lymphocytes points towards a diagnosis of reactive follicular hyperplasia.

We are grateful to Miss Angela Wright for typing $\vec{\omega}$ the manuscript. The camera lucida was kindly donated by The Royal Society.

\section{References}

${ }^{1}$ Custer RP. Pitfalls in the diagnosis of lymphoma and leukaemia from the pathologist's point of view. In: Proceedings of the Second National Cancer Conference, 1952, Vol 1. New Yor American Cancer Society, Inc 1954:554-7.

${ }^{2}$ Rappaport H. Tumors of the hematopoietic system. In: Atlas tumor pathology, Sect III, Fascicle 8. Washington DC: Armed Forces Institute of Pathology, 1966.

${ }^{3}$ Nathwani BN, Winberg CD, Diamond LW, Bearman RM, Kim H. Morphologic criteria for the differentiation of follicular lymphoma from florid reactive follicular hyperplasia: A study of 80 cases. Cancer 1981;48:1794-1806.

${ }^{4}$ Wright DH. The identification and classification of nonHodgkin's lymphoma: a review Diagn Histopathol 1982;5:73-111.

s Crocker J, Jones EL, Curran RC. A quantitative study of $\overline{0}$ $\alpha$-naphthyl acetate esterase-positive cells in non-Hodgkin's lymphomas and reactive lymph nodes. J Clin Pathol $\Omega$ 1982;35:1066-8.

- Crocker J, Jones EL, Curran RC. Study of nuclear diameters in non-Hodgkin's lymphoma. J Clin Pathol 1982;35:954-8.

${ }^{7}$ Crocker J, Jones EL, Curran RC. A comparative study of nuclear $\bigcirc$ form factor, area and diameter in non-Hodgkin's lymphomas and reactive lymph nodes. J Clin Pathol 1983;36:298-302.

${ }^{8}$ Crocker J, Jones EL, Curran RC. A quantitative study of the size of benign and malignant lymphoid follicles. J Clin Pathol $\frac{D}{O}$ 1983;36:1055-61.

9 Steer MW. Understanding cell structure. Cambridge, London, $\mathrm{N}$ New York: Cambridge University Press, 1981.

${ }^{10}$ Lennert K. Malignant lymphomas other than Hodgkin's disease. New York: Springer-Verlag, 1978.

"Crocker J, Jones EL, Curran RC. The form factor of $\alpha$-naphthyl $\mathcal{\omega}$ acetate esterase-positive cells in non-Hodgkin's lymphomas and reactive lymph nodes. J Clin Pathol 1983;36:303-6.

12 Crocker J. The enzyme histochemistry of lymphomas. University of Cambridge: MD thesis, 1983.

Requests for reprints to Dr J Crocker, Histopathology Department, East Birmingham Hospital, Bordesley Green East, Birmingham, B9 5ST, England. 